DOI: $10.2478 / \mathrm{v} \cdot 10169-012-0028-6$

\title{
ASSESSMENT OF SKID RESISTANCE OF ASPHALT MIXTURES IN LABORATORY CONDITIONS
}

\author{
W. GARDZIEJCZYK ${ }^{1}$, M. WASILEWSKA ${ }^{2}$
}

\begin{abstract}
The aggregate applied for the wearing course has a significant influence on skid resistance of road surfaces. However, it is difficult to evaluate the behaviour of road surface in use on the basis of the Polished Stone Value (PSV) determined for the aggregate according to the so called 'British method'. The British method, which is currently used in many countries, does not allow to determine the influence of neither the grain size of the aggregate nor the type of the wearing course on skid resistance of road surface. The present paper suggests a method for evaluation of the British Pendulum Number $(B P N)$ for road surfaces in laboratory conditions. The authors assumed the $B P N$ for polished slabs, made from asphalt mixtures, as the criterion. The index was measured with the British Pendulum Tester. The simulation of the process was conducted on research stand (called slab polisher) built at Bialystok University of Technology (BUT). The results of laboratory tests indicate that surfaces from asphalt concrete (AC) have slightly higher values of $B P N$ in comparison with the values determined for surfaces made from stone mastic asphalt (SMA).
\end{abstract}

Key words: aggregate, road surface, $B P N$, skid resistance, $P S V$, asphalt mixture.

\section{INTRODUCTION}

Skid resistance of a road surface plays an important role in ensuring the safety of road traffic. It depends on the type of surface and its technical condition, how long the surface has been in use, the texture of wearing course, and the properties of materials used [4]. In the case of lower speeds the microtexture of the surface is crucial, whereas in the case of higher speeds macrotexture and microtexture of wearing course of the surface are the most essential. The methods of surface macrotexture assessment are based on geometrical description of irregularity of surface with wave lengths of 0.5 $\mathrm{mm}$ to $50 \mathrm{~mm}$ and frequency in the range of 0.1 to $20 \mathrm{~mm}$, and they are relatively well known. The basic parameters which characterize macrotexture are Meter Texture Depth (MTD) and Mean Profile Depth (MPD) (ISO 13473).

${ }^{1} \mathrm{PhD}$, DSc, Eng, Univ. Professor, Faculty of Civil and Environment Engineering, Bialystok University of Technology, Bialystok, Poland, e-mail: w.gardziejczyk@pb.edu.pl

${ }^{2} \mathrm{PhD}$, Faculty of Civil and Environment Engineering, Bialystok University of Technology, Bialystok, Poland, e-mail: marta.wasilewska@pb.edu.pl 
The description of surface microtexture i.e. irregularities of $0.5 \mathrm{~mm}$ wave length and frequency of 0.001 to $0.5 \mathrm{~mm}$ appears to be a significantly more complicated problem. Knowledge related to microtexture, especially concerning the changes which occur in the course of its use, is crucial in the context of traffic safety, particularly on wet surfaces $[19,20,26]$.

There are two approaches applied for the assessment of surface microtexture:

- on the basis of measurement of friction coefficient conducted on the actual road sections with the use of mobile devices (e.g. SCRIM, Norsemeter ROAR, SRT-3, Griptester) and portable devices (e.g. British Pendulum Tester, Dynamic Friction Tester - DFT) [3, 25],

- on the basis of geometrical description of microirregularities, e.g. using laser and optical microscopy, photogrammetry [7, 9, 22].

In actual traffic conditions water and tiny mineral particles, due to the effect of car tyres, polish the protruding grains of aggregate which results in slippery road pavement. The main factors which determine aggregate's resistance to polishing are: the content and hardness of particular minerals which make up the rock, the structure and texture (size, the extent of crystallization of minerals and the way the minerals are composed, contact between minerals grains, etc.), porosity, and the extent of rock's weathering $[5,12,21,23]$.

The process of aggregate grains polishing occurs mainly in spring and summer while in winter there occurs regeneration of surface microtexture leading to changes in the friction coefficient during the year [16].

It is possible to recreate the process of stone polishing by car tyres in laboratory conditions. The test which allows to determine the PSV (Polished Stone Value) index, according to EN 1097-8:2009 standard, is referred to as the British method. It is the most commonly applied method to test the resistance to polishing of road aggregates in laboratory conditions. This test is carried out by using two devices: the accelerated polishing machine and the British pendulum tester.

However, the British method to assess the resistance to polishing of road aggregates does not allow to determine to what extent these aggregates' susceptibility to polishing factors affects skid resistance of road pavement when it is in use.

Currently the Wehner/Schulze method developed in Germany is becoming more and more popular to investigate skid resistance in laboratory conditions (Germany, France, Austria, the United Kingdom). It is used for both aggregates and asphalt mixtures $[1,8,14]$. There is also an option to test surface specimens from road sections in use. Literature shows the results of tests into skid resistance conducted with Wehner/Schulze machine. The researchers have confirmed concordance of this method with the results obtained with the British method $[2,6,13]$.

In many countries, including Poland, the measurements of microtexture have been so far conducted only indirectly, namely through the measurements of friction coefficient using mobile devices on new road surfaces or the ones in use. Such an approach makes it impossible to conduct assessment of the skid resistance for asphalt mixtures at 
the design stage. This fact and lack of Wehner/ Schulze machine resulted in a decision to build a research stand (the so called 'slab polisher') at the Bialystok University of Technology which, together with the British pendulum tester, will allow to assess skid resistance of asphalt mixtures in laboratory conditions.

The aim of the conducted tests and analyses was to evaluate the effect of the aggregate type and grain size, as well as the type of asphalt mixture on the basis of BPN (British Pendulum Number) according to ASTM E303 - 93: 2008 standard. The results of these tests are discussed in the present paper.

\section{RESEARCH STAND AND ASSESSMENT OF SKID RESISTANCE FOR AGGREGATES}

Slab polisher for accelerated polishing of aggregates and asphalt mixtures in laboratory conditions, which was built at the Bialystok University of Technology, consists of three smooth rubber wheels. The wheels move at $50 \pm 2$ rotations per minute (Fig. 1) [24]. The load of $68 \mathrm{~kg}$ is evenly distributed on the three wheels. The designers of the polisher applied the experience of researchers from the United States and New Zealand [17, $18,27]$.

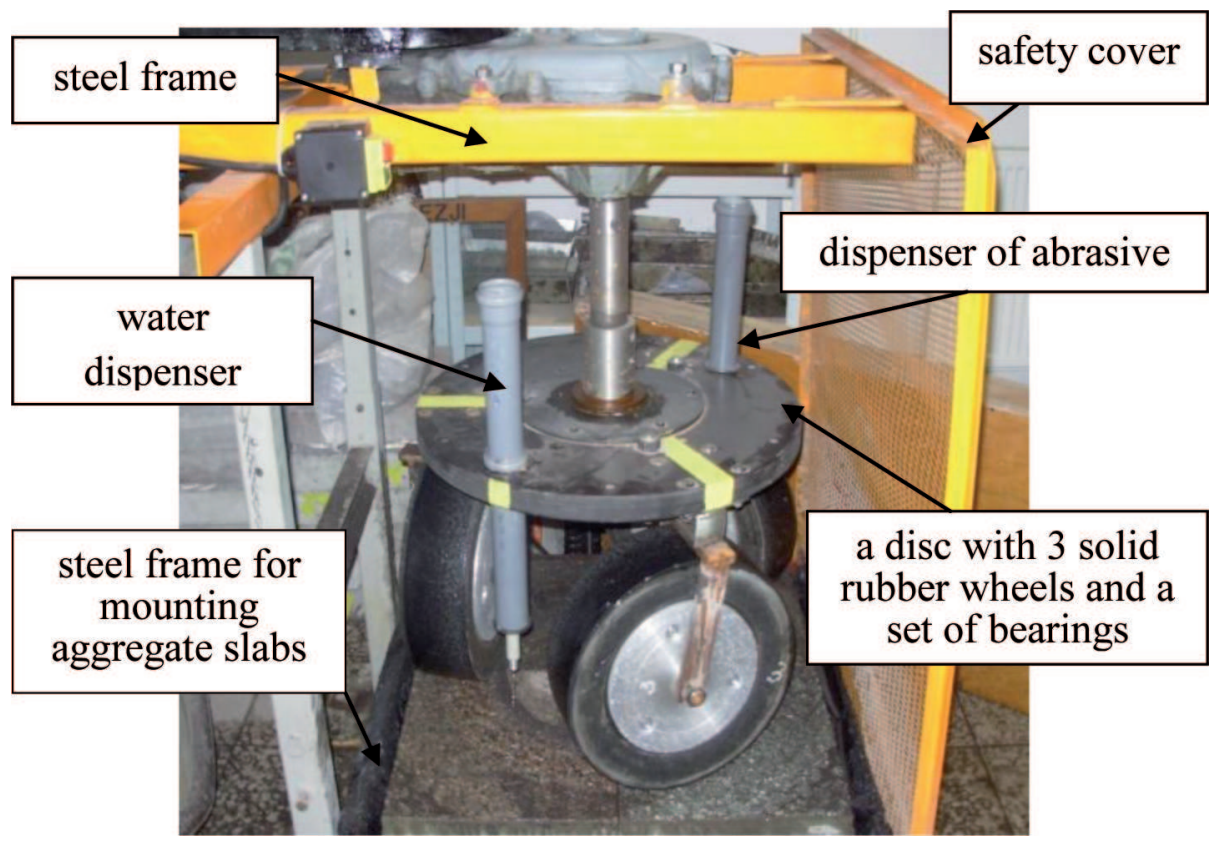

Fig. 1. Research stand for polishing aggregates and asphalt mixtures - slab polisher.

Testing of the device was conducted by comparing friction index $(S)$ of the investigated aggregates determined with the British method (Fig. 2) with $B P N$ for the same aggregates determined on test slabs polished with the slab polisher (Fig. 3) 
Testing of the machine built at the Bialystok University of Technology was conducted on igneous aggregates (granodiorite $P S V 49$, gabbro $P S V$ 55), sedimentary rock aggregates (quartzite sandstone PSV 58, dolomite PSV 43), postglacial aggregates ( $P S V$ $52)$ and steelmaking slag aggregates ( $P S V$ from 52 to 57). The aggregate specimens had the following sizes: $4 / 6.3,8 / 10,10 / 12.8,12.8 / 16$.

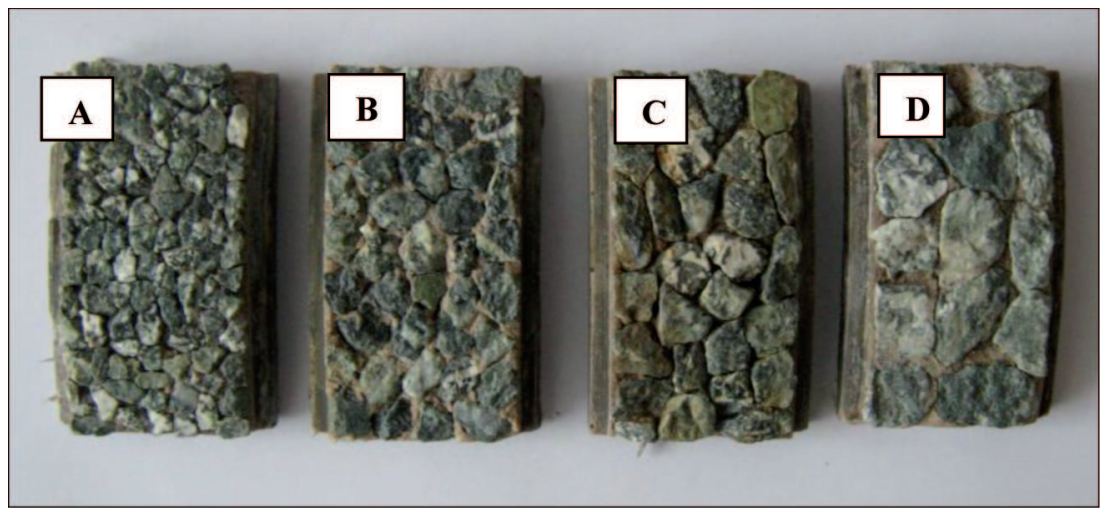

Fig. 2. Specimens of gabbro aggregate for test into resistance to polishing according to the British method (aggregate size: A - 4/6.3, B - 8/10 - standard specimen, C - 10/12.8, D - 12.8/16).

The specimen polishing cycle according to the British method was carried out in two phases, each lasting 3 hours. The duration of slab polishing with the machine built by the authors was determined on the basis of preliminary tests. Polishing was also done in two phases, however each phase lasted 6 hours. In both cases, in the first phase, the coarse emery was used (size $300 / 600 \mu \mathrm{m}$ ) and water. In the second phase fine emery was used (sizes smaller than $53 \mu \mathrm{m}$ ) and water.

Fig. $4-6$ show regression relationships between friction index $(S)$ determined according to the British method, and $B P N$ values from surface of aggregates which were polished on the slab polisher, depending on the type of aggregate (Fig. 4), grain size (Fig. 5) and finally for all the investigated aggregates (Fig. 6).

Thus established coefficients of determination $R^{2}$ confirmed good conformity of $B P N$ and $S$ values determined with both methods. This resulted in a decision to conduct investigations into $B P N$ on asphalt mixtures polished with the machine described above.

\section{BPN VALUES OF ASPHALT MIXTURES IN LABORATORY CONDITIONS}

The asphalt concrete mixtures and SMA specimens were selected, with the following graining: 0/6.3;0/12.8 and 0/16 for the detailed $B P N$ values investigations into road pavements in laboratory conditions. Aggregates with different degrees of susceptibility to polishing factors were applied in the production of those mixtures (aggregates: granodiorite - PSV 49, postglacial - PSV 52, gabbro - PSV 55). Aggregate grain 


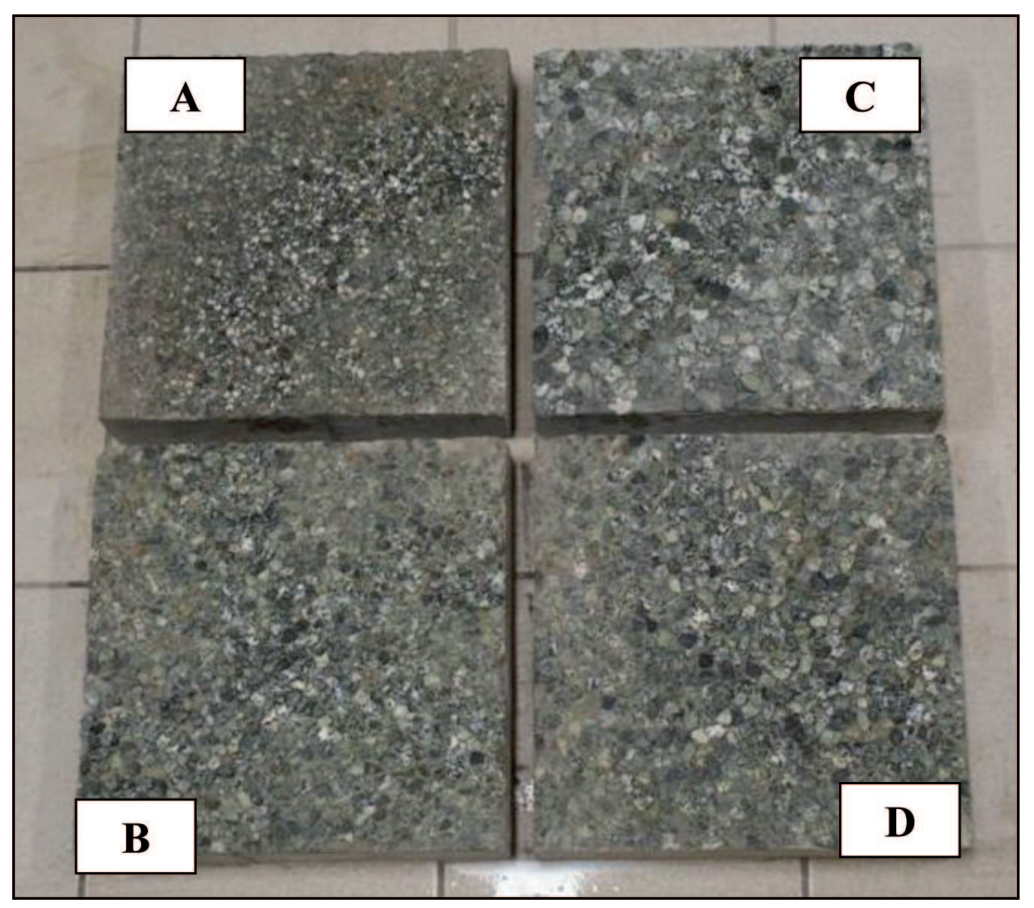

Fig. 3. Specimens of gabbro aggregate for test on slab polisher; grain size: A - 4/6.3, B - 8/10, C - 10/12.8, D - 12.8/16.

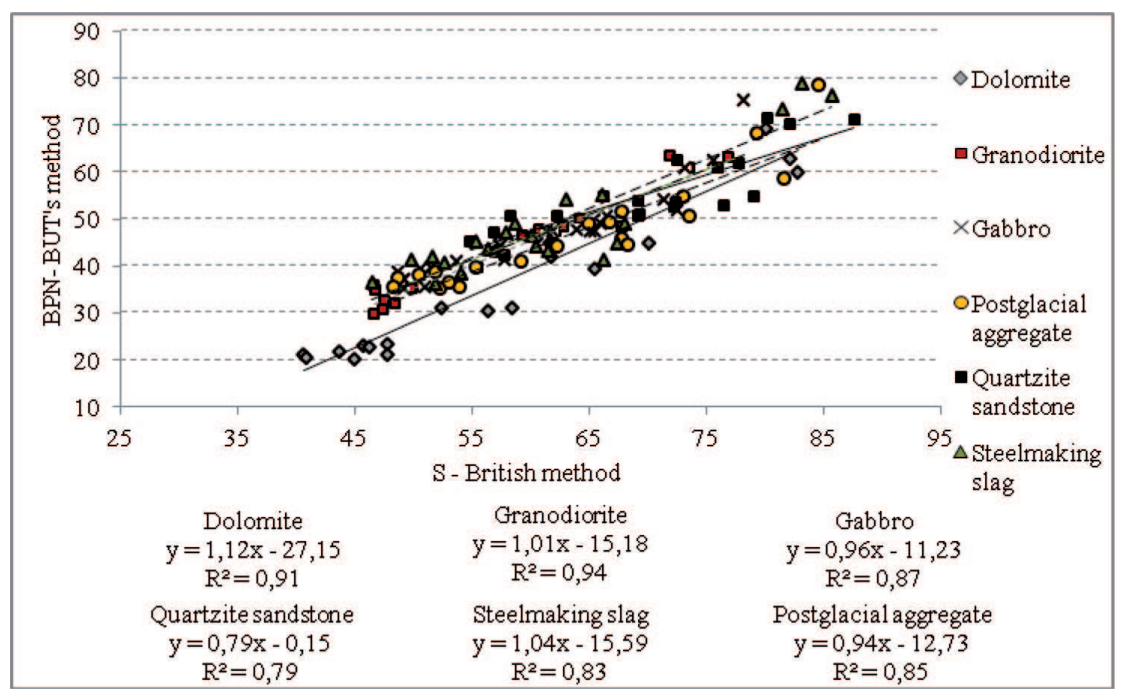

Fig. 4. Relation between the $B P N$ and $S$ values depending on aggregate type. 


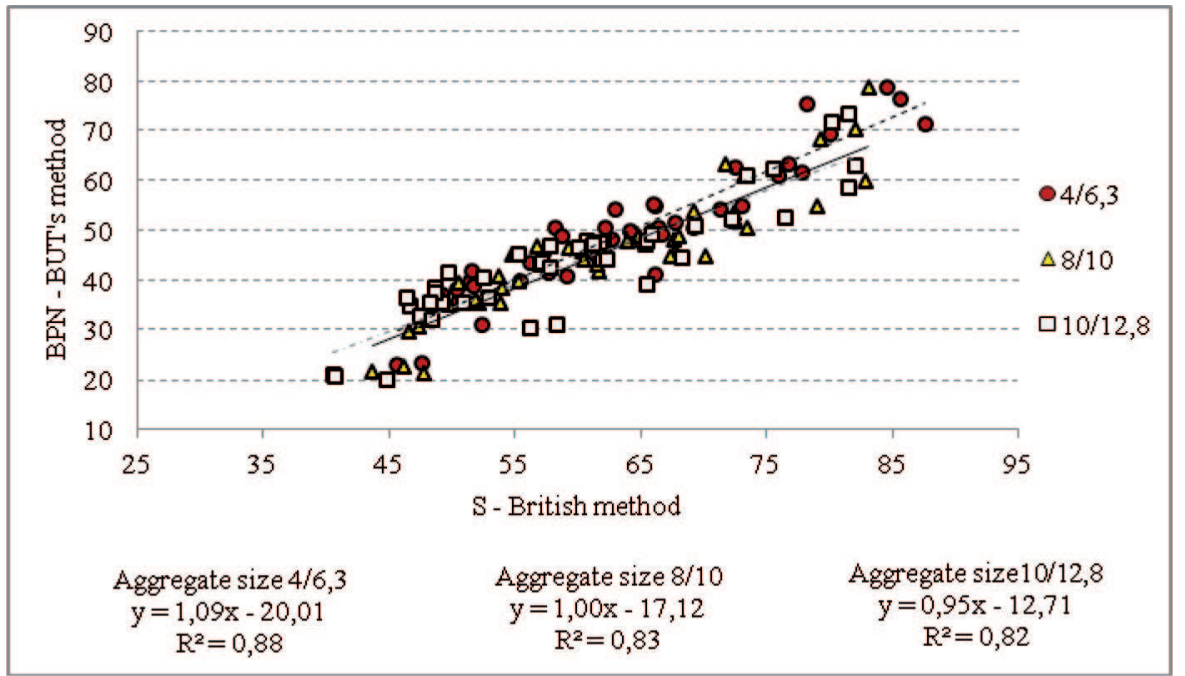

Fig. 5. Relation between the $B P N$ and $S$ values depending on the grain size of aggregates.

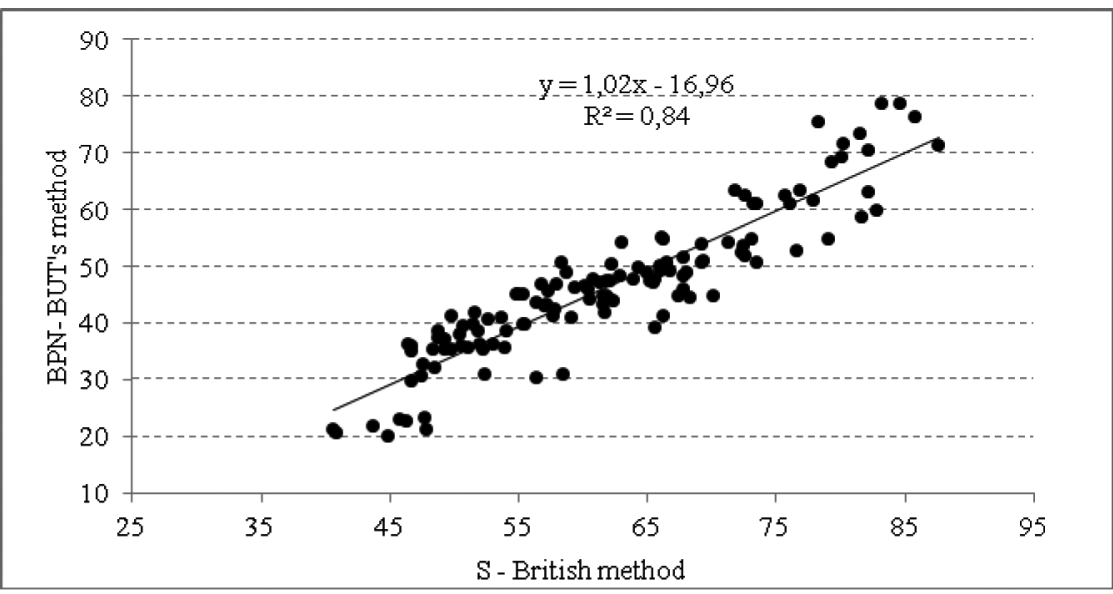

Fig. 6. Relation between the $B P N$ a $S$ values all the investigated aggregates. 
sizes were assumed according to the recent legal regulations in Poland related to asphalt mixtures used for wearing courses of road pavements (at present the following graining is used: $0 / 5,0 / 8$ and $0 / 11$ ).

Asphalt mixture specimens were made in the research laboratory at the Bialystok University of Technology. The mixtures were compacted with a steel roller whose unit pressure is similar to the pressure of rollers used in situ. Compaction for the obtained slabs exceeded $98 \%$.

The slabs, before they were polished, had been subjected to measurements of macrotexture with a profilograph and the method of sand patch test. In this way, the authors determined the values of MTD and MPD. Since the British Pendulum Tester reflects the conditions of a vehicle skidding at $10 \mathrm{~km} / \mathrm{h}$ and surface macrotexture has a significant effect on skid resistance of the surface at higher speeds, further discussion does not include the analysis of the influence of macrotexture on the BPN value.

Table 1 includes the selected characteristics of the asphalt mixtures investigated in laboratory tests.

Table 1

Properties of the asphalt mixtures.

\begin{tabular}{|l|c|c|c|c|c|c|}
\hline \multirow{2}{*}{ Characteristics of the asphalt mixtures } & \multicolumn{3}{|c|}{ AC } & \multicolumn{3}{c|}{ SMA } \\
\cline { 2 - 7 } & $0 / 6.3$ & $0 / 12.8$ & $0 / 16$ & $0 / 6.3$ & $0 / 12.8$ & $0 / 16$ \\
\hline Asphalt content, [\%] & $6.0-6.7$ & $4.7-5.5$ & $4.7-5.3$ & $6.2-7.3$ & $5.8-6.2$ & $5.7-6.0$ \\
\hline Void content, [\%] & $2.3-4.3$ & $2.3-3.2$ & $2.3-2.7$ & $3.0-3.5$ & $3.3-3.6$ & $3.4-3.8$ \\
\hline Fraction content $<2 \mathrm{~mm},[\%]$ & $45-60$ & $40-45$ & $34-39$ & $27-29$ & $20-24$ & $20-23$ \\
\hline Macrotexture $-M T D$ value, $[\mathrm{mm}]$ & 0.38 & 0.54 & 0.67 & 0.57 & 0.93 & 1.13 \\
\hline Macrotexture $-M P D$ value, $[\mathrm{mm}]$ & 0.36 & 0.49 & 0.64 & 0.53 & 1.04 & 1.28 \\
\hline
\end{tabular}

Three $300 \times 300 \times 50 \mathrm{~mm}$ slabs were made from each designed mixture. In total 54 slabs were made and each slab was polished in independent cycles consisting of two six-hour phases. Fig. 7 shows specimens of slabs from SMA.
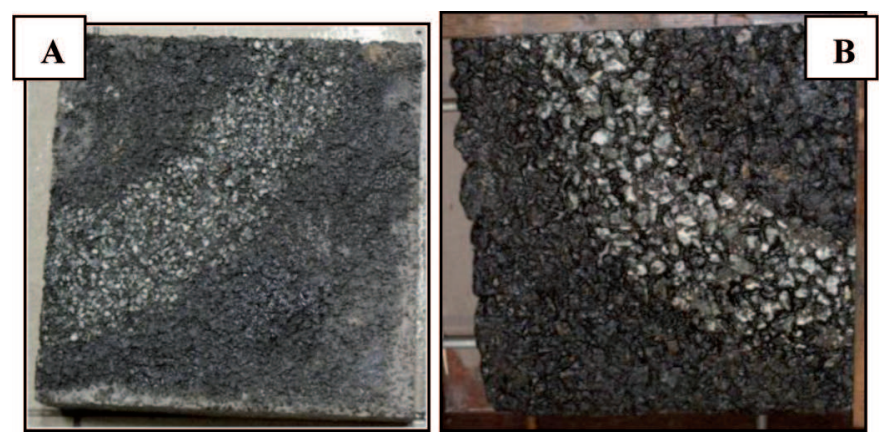

Fig. 7. The surfaces of the polished SMA slabs with gabbro aggregate: $A-0 / 6.3$ and $B-0 / 16$. 
Measurements of $B P N$ were conducted on the surfaces of slabs before polishing, after the $1^{s t}$ phase of polishing and after polishing was finished. The measurements were made with the British pendulum tester with contact path of $126 \mathrm{~mm}$. The paper analyses only $B P N$ which were taken after the process of polishing was finished.

The values of $B P N$ which characterize skid-resistance of the investigated asphalt mixtures in laboratory conditions were obtained in the following way:

- on each polished slab 3 points were selected and for each of those five measurements were taken; measurements 3, 4 and 5 formed the basis for calculating the $B P N$ for the investigated point: the arithmetic mean value from $B P N$ at the 3 points was used for the particular slab (Fig. 8),

- $B P N$ values for each asphalt mixture were calculated as the arithmetic mean value from the results obtained on 3 slabs.

Table 2 presents $B P N$ values and their standard deviations $\sigma$.

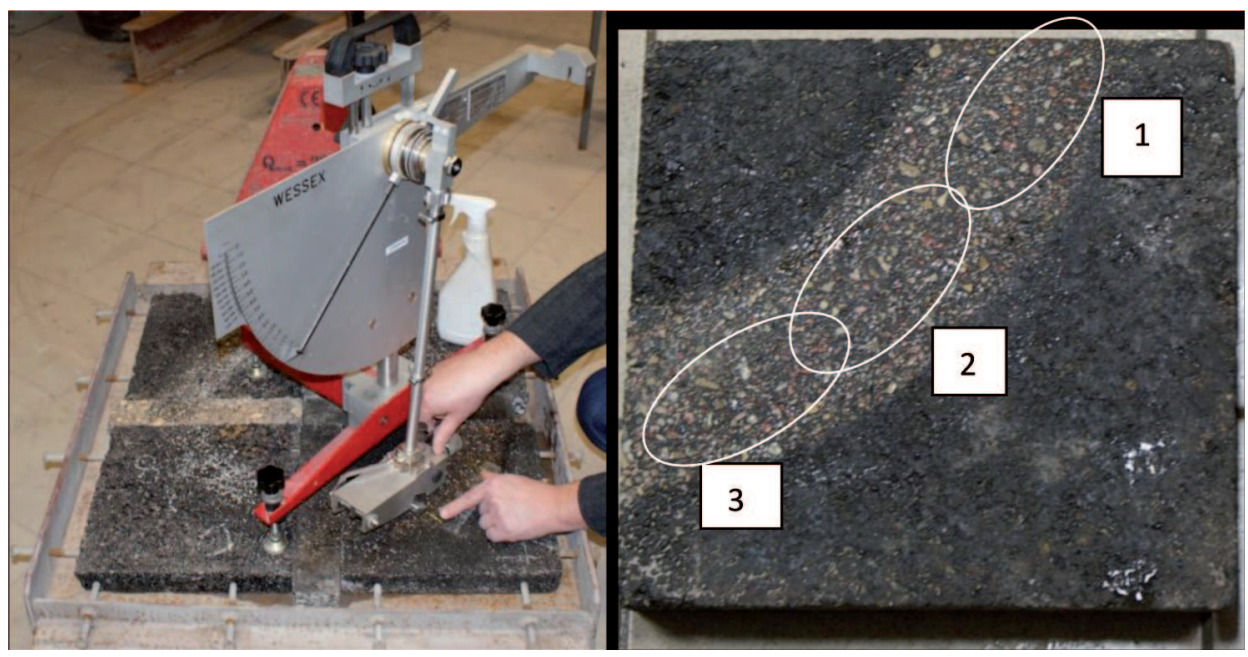

Fig. 8. $B P N$ test on slabs from asphalt mixture.

In the case of SMA by far the smallest decrease of $B P N$ values for the investigated mixture, along with the change of the maximum aggregate graining, was found for the aggregate with $P S V 52$ (by 0.7 with the change of maximum graining from $6.3 \mathrm{~mm}$ to $16 \mathrm{~mm}$ ). Slightly bigger decrease of $B P N$ values was found for the aggregate with $P S V 55$ (by 1.3, the change of maximum graining from 6.3 to $16 \mathrm{~mm}$ ) and the biggest decrease of $B P N$ was found for granodiorite aggregate with PSV 49 (by 5.0, the change in maximum graining from $6.3 \mathrm{~mm}$ to $16 \mathrm{~mm}$ ). Significant susceptibility to polishing in the case of granodiorite aggregate is the effect of its fine grain structure and a large content of hard minerals (approximately 80\%). The tests conducted by Huang [10] also proved that grains of larger sizes are more prone to polishing. 
$B P N$ values for the investigated asphalt mixtures.

\begin{tabular}{|c|c|c|c|c|c|c|c|}
\hline \multicolumn{2}{|c|}{$\mathrm{AC}$} & \multirow{2}{*}{$B P N$} & \multirow{2}{*}{$\Sigma$} & \multicolumn{2}{|c|}{ SMA } & \multirow{2}{*}{$B P N$} & \multirow{2}{*}{$\sigma$} \\
\hline$U_{\max }$ & $P S V$ & & & $U_{\max }$ & $P S V$ & & \\
\hline \multirow{3}{*}{6.3} & 49 & 40.6 & 2.05 & \multirow{3}{*}{6.3} & 49 & 40.3 & 1.64 \\
\hline & 52 & 42.1 & 1.17 & & 52 & 41.3 & 1.15 \\
\hline & 55 & 42.0 & 1.05 & & 55 & 43.3 & 1.97 \\
\hline \multirow{3}{*}{12.8} & 49 & 41.6 & 3.15 & \multirow{3}{*}{12.8} & 49 & 37.5 & 2.55 \\
\hline & 52 & 45.3 & 0.21 & & 52 & 40.7 & 0.38 \\
\hline & 55 & 46.5 & 0.57 & & 55 & 42.4 & 1.26 \\
\hline \multirow{3}{*}{16} & 49 & 38.6 & 3.50 & \multirow{3}{*}{16} & 49 & 35.3 & 0.60 \\
\hline & 52 & 43.1 & 2.49 & & 52 & 40.6 & 1.46 \\
\hline & 55 & 44.6 & 0.98 & & 55 & 41.0 & 0.70 \\
\hline
\end{tabular}

PSV 49 - granodiorite aggregate, PSV 52 - postglacial aggregate,

PSV 55 - gabbro aggregate

In the case of SMA, with graining at 0/6.3, the increase in aggregate's $P S V$ from 49 to 55 resulted in the increase of $B P N$ value by 3.0, whereas with aggregate graining at $0 / 12.8$ and $0 / 16$ by 4.9 and 5.7 respectively. When aggregate's $P S V$ was changed from 52 to 55 , the value of $B P N$ increased by 2.0 with aggregate graining at $0 / 6.3$ and by 1.7 at aggregate graining at $0 / 12.8$ and by 0.5 at aggregate graining at $0 / 16$.

In the case of asphalt concrete (AC) the highest values of $B P N$ were obtained for aggregate graining at $0 / 12.8$. The authors found the following decreases of $B P N$ values along with the change of the maximum aggregate graining:

- when an aggregate with PSV 49 was used the value decreased by 1.0 - with graining at $0 / 6.3$ and by 3.0 with graining at $0 / 16$,

- when an aggregate with PSV 52 was used - by 3.2 and 2.2 respectively,

- when an aggregate with PSV 55 was used - by 4.5 and 1.9 respectively.

The analysis of the effect of aggregate's $P S V$ on $B P N$ values of AC and SMA mixtures indicates that when an aggregate with $0 / 6.3$ graining is used, the change in the value of $P S V$ from 49 to 52 results in the increase of $B P N$ value by 1.5 and in the case of $\mathrm{AC}$ by 1.0 , in the case of SMA, with $0 / 12.8$ graining - by 3.7 and 3.2 respectively and with $0 / 16$ graining - by 4.5 and 5.3 respectively. The change in aggregate's PSV from 49 to 55, with 0/6.3 graining results in the increase of PSV by 1.4 in the case of $\mathrm{AC}$ and by 2 in the case of SMA, with 0/12.8 aggregate graining - by 4.9 for AC and for SMA, with 0/16 aggregate graining - by 6.0 for AC and by 5.7 for SMA.

The analysis indicates that the type of asphalt mixture and the type and graining of the aggregate have an effect on the $B P N$ for road pavements. One of the reasons of slightly higher $B P N$ for asphalt concrete in comparison with SMA surface, mainly for aggregate graining at $0 / 12.8$ and $0 / 16$, could be a bigger content of sand fraction $(<2 \mathrm{~mm})$ in asphalt concrete mixture. This fact was also noticed in [11] where the evaluation of asphalt mixtures with bigger content of sand fraction was more positive. 
4. The INFLUENCE OF AGgREgate CHARACTERISTICS AND TYPE OF ASPHALT MIXTURE ON BPN VALUES OF THE SURFACE

In order to explain the influence of aggregate type and technology used to produce the wearing course on skid resistance of road surface the authors defined relations between $B P N(\hat{y})$ and maximum aggregate size $U_{\max }\left(x_{1}\right.$ factor) and $P S V$ indicator of aggregate ( $x_{2}$ factor). The analysis was conducted independently for two technologies - asphalt concrete and SMA and it was based on the results of $B P N$ values obtained after the $2^{\text {nd }}$ phase of polishing in slab polisher as shown in $\S 3$. The authors used the theory of experiment planning and tools for regression analysis [28]. Mathematical models were developed for $B P N$ depending on $x_{1}$ and $x_{2}$ factors by assuming the polynomial of the $2^{\text {nd }}$ degree in the following form:

$$
\hat{y}=b_{0}+b_{1} x_{1}+b_{2} x_{2}+b_{11} x_{1}^{2}+b_{22} x_{2}^{2}+b_{12} x_{1} x_{2}
$$

where: $b_{0}, b_{1}, \ldots b_{22}$ - coefficients of the approximating polynomial.

The values of $x_{1}$ and $x_{2}$ variables were coded on three levels: -1, 0, 1:

- $x_{1}$ factor - maximum aggregate size in mineral-asphalt mixture $U_{\max }: U_{\max }(8 \mathrm{~mm})$ $=,-1$ ": equivalent to $0 / 6.3 \mathrm{~mm} ; U_{\max }(12 \mathrm{~mm})=,, 0$ ": equivalent to $0 / 12.8 \mathrm{~mm}$;

$U_{\max }(16 \mathrm{~mm})=,, 1$ ": size of $0 / 16 \mathrm{~mm}$;

- $x_{2}$ factor $-P S V$ of an aggregate: 49 (,-1”), 52 (,0”), 55 (,1”).

Thus $x_{1}$ and $x_{2}$ factors assumed values on three levels $(-1 ; 0 ; 1)$, and their coding was done according to the formula (4.2):

$$
x_{i}=\frac{2\left(\tilde{X}_{i}-X_{r}\right)}{X_{\max }-X_{\min }}
$$

where: $\tilde{X}_{i}$ - the actual values of $x_{i}$ factor, $X_{r}$ - the mean actual value of the factor, $X_{\max }$ - the maximum value of $x_{i}$ factor, $X_{\min }$ - the minimal value of $x_{i}$ factor.

\section{Asphalt concrete}

The values of $b_{i}$ coefficients were determined with the least squares method and the obtained form of the regression model is as follows:

$$
\hat{y}=45.22+0.26 x_{1}+2.04 x_{2}-2.62 x_{1}^{2}-1.15 x_{2}^{2}+0.24 x_{1} x_{2} \quad S_{e}=0.48
$$

After checking the significance of model coefficients on level of significance $\alpha=0.05$, eliminating the irrelevant coefficients and after checking the adequacy of the model the relation has the form:

$$
\hat{y}=44.45+2.04 x_{2}-2.62 x_{1}^{2} \quad S_{e}=1.22
$$

Interpretation of the model with the coded values shows that the increase of PSV by 3 units (e.g. from PSV 49 to PSV 52) results in the increase of $B P N$ value by 2.04 
units with maximum aggregate size on the same level. However, the negative square effect of $x_{1}$ factor indicates that the highest value of $B P N$ is obtained when graining at ' 0 ' level is used. Both the choice of the mixture with graining equivalent to '-1' and ' 1 ' results in the decrease of $B P N$ by 2.62. The negative effect of $x_{1}$ factor is eliminated by the positive effect of $x_{2}$ factor. This means that the addition of aggregate with higher $P S V$ enables to obtain higher value of $B P N$ at the same graining.

\section{Stone mastic asphalt SMA}

Values of $b_{i}$ coefficients were determined with the least squares method and the obtained form of the regression model is as follows:

$$
\hat{y}=40.86-1.34 x_{1}+2.30 x_{2}+0.05 x_{1}^{2}-0.91 x_{2}^{2}+0.07 x_{1} x_{2}, \quad S_{e}=1.03
$$

After checking the significance of model coefficients on level of significance $\alpha=0.05$, eliminating the irrelevant coefficients and checking the adequacy of the model the relation has the form:

$$
\hat{y}=40.29-1.34 x_{1}+2.30 x_{2} \quad R^{2}=0.86, \quad S_{e}=1.06
$$

The regression model shows linear dependence of the influence of graining and PSV index on the value of $B P N$. The positive linear effect $\left(b_{2}\right)$ of $x_{2}$ factor means that the increase of the value of $P S V$ by 3 units will result in the increase of $B P N$ value by 2.30 while graining remains at the same level. On the other hand, the negative effect of $x_{1}$ factor indicates that the increase of the maximum graining of the mixture by $4 \mathrm{~mm}$ results in the decrease of $B P N$ by 1.30 when the aggregate with the same value of $P S V$ index is used. It should be noted that the negative effect of $x_{1}$ factor is eliminated by the positive effect of $x_{2}$ factor. The values $b_{1}=-1.34$ and $b_{2}=2.30$ indicate greater influence of $P S V$ than the maximum level of graining on $B P N$ of SMA mixture.

After transforming of the developed formulas (4.4) and (4.6) to the form which considers the actual values of factors (maximum aggregate size $-U_{\max }, P S V$ indicator) on the basis of formula (4.2) the following regression models were obtained:

$$
\begin{gathered}
B P N^{A C}=-4.75+0.68 P S V+2.50 U_{\max }-0.11 U_{\max }^{2} \\
B P N^{S M A}=3.58+0.76 P S V-0.28 U_{\max }
\end{gathered}
$$

Figure 9 presents the range of $B P N$ changes depending on the maximum aggregate graining and $P S V$. It indicates that mixtures of best solution are those of asphalt concrete with the maximum aggregate graining from 10 to $13 \mathrm{~mm}$ and $P S V \geq 54$. In the case of SMA mixtures on the basis of the aggregate with $P S V \geq 54$, graining from 10 to $13 \mathrm{~mm}, B P N$ are obtained which are by 4 units lower than those for asphalt concrete. 

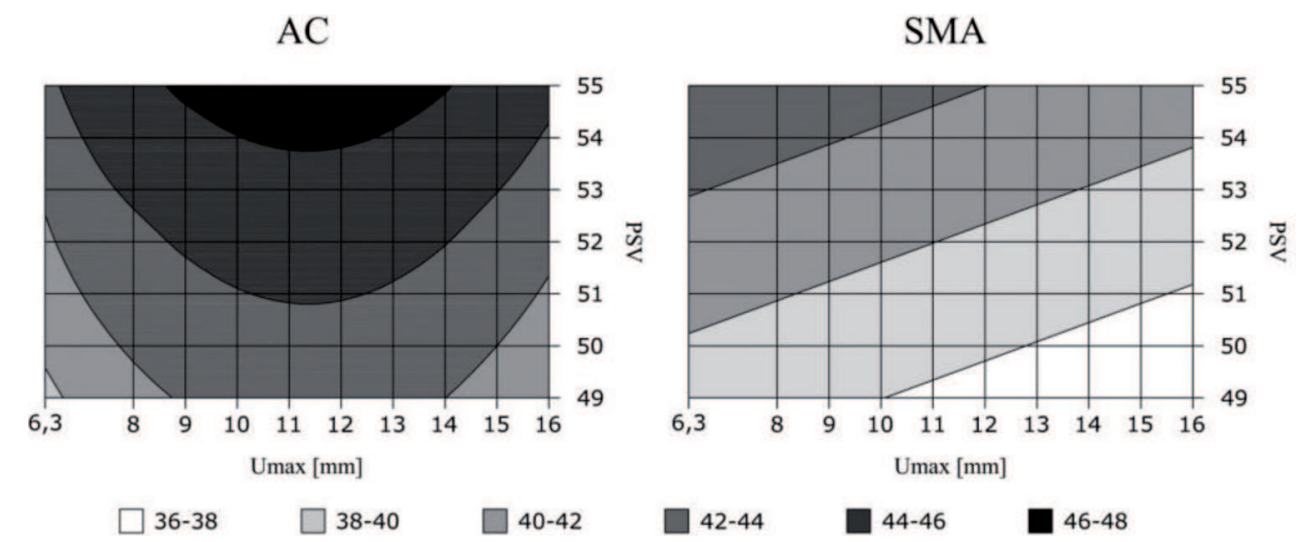

Fig. 9. The range of $B P N$ depending on $P S V$ and aggregate graining.

\section{Conclusions}

The results of the tests conducted in the research laboratory of Bialystok University of Technology indicate the following conclusions:

1. Determination coefficients $R^{2}$, between $B P N$ values for specimens of aggregates polished on the slabs polished on the slab polisher and friction index $S$ for specimens of aggregates polished according to the British method confirmed the possibility of applying the suggested method to conduct investigations into BPN values of surfaces from asphalt mixtures.

2. The type of asphalt mixture and the graining and the type of aggregate have an effect on $B P N$ of a road surface; however, this effect is varied and more significant when coarser graining of the aggregate is used.

3. Higher values of $B P N$ were obtained when the aggregate with the same characteristics was used for mixtures from asphalt concrete when compared to SMA mixtures. $B P N$ values determined for both mixtures with graining at $0 / 6.3$ were practically identical (the difference of 1.5 ), with graining at $0 / 12.8$ and $0 / 16$ the differences ranged from 3.2 to 5.3. The cause of such differences might be the effect of greater content of sand fraction in asphalt concrete mixture.

4. The authors suggest further investigations into $B P N$ values in laboratory conditions with the use of slab polisher, also with reference to other asphalt mixtures and a wider group of aggregates. The results of investigations ought to be verified on surfaces in-situ. 


\section{REFERENCES}

1. B. Allen, P. Philips, D. Woodward, A. Woodside, Prediction of UK surfacing skid resistance using Wehner Schulze and PSV. $2^{\text {nd }}$ International safer roads conference, 12-16 May, Cheltenham, United Kingdom, 2008.

2. H. Arampamoorthy, J. Partick, Potential of Wehner-Schulze test to predict the on-road friction performance of aggregate. NZ Transport Agency research report 443. New Zealand, 2011.

3. M. Bustos, T. Echaveguren, H. Solmininac, A. Caroca, Development of correlation equations between different measurements of skid resistance in pavements. Indian Journal of Engineering \& Materials Sciences, 13, 2, p. 117-122, 2006.

4. P. Cenek, R. Davies, R. Henderson, In service skid resistance performance of aggregate. Proc International Conference on Managing Road Runway Surface to improve safety, United Kingdom, 2008.

5. M.-T. Do, Relation entre la microtexture et l'adherence. Adhérence - Numéro spécial 254. Bulletin des Laboratoires des Points et Chaussées, Avril - Mai - Juin 2005.

6. M.-T. Do, Z. TAng, M. Kane, F. Larrard, Pavement polishing-Development of a dedicated laboratory test and its correlation with road results. Science Direct Wear, 263, 1-6, p. 36-42, 2007.

7. M.-T. Do, M. Kane, Z. TANG, F. Larrard, Physical model for the prediction of pavement polishing. Science Direct Wear, 267, 1-4, p. 81-85, 2009.

8. A. Dunford, The Wehner Schulze machine and its potential use to improve aggregate specification. $2^{\text {nd }}$ International safer roads conference, 12-16 May, Cheltenham, United Kingdom, 2008.

9. M. Ergun, S. Iyinam, A.F. Iyinam, Prediction of road surface friction coefficient using only macroand microtexture measurements. Journal of Transportation Engineering. 131, 4, 2005.

10. Ch. Hunng, Texture characteristics of unpolished and polished aggregate surface. Tribology International, 43, 1, p. 188-196, 2010.

11. P. Dupont, B. Faure, Aide au choix des couches de roulement vis-a-vis de l'adherence. 4th International Symposium "SURF 2000": Pavement Surface Characteristics" - Nantes-France 2000.

12. W. GaRDZIEJCZyK, M. WasilewsKa, Resistance to polishing of mineral-asphalt mixes based on mineral aggregate with different PSV Index [in Polish], Drogownictwo nr 9, p. 305-309, 2010.

13. S. Hamlat, P. Marsac, M.-T. Do, R. Morgades, I. Drouadaine, Evaluation de la resistance au polissage des materiaux de chaussees avec la machine Wehner et Schule. Revue Generale des Routes, No. 885, 2010.

14. M. Kane, M.-T. Do, J.M. Piau, On the Study of Polishing of Road Surface under Traffic Load. Journal of Transportation Engineering, 136, 1, p. 45-50, 2010.

15. C.F. JefF Wu, M.S. Hamada, Experiments: planning, analysis, and parameter design optimization. Wiley, 2009.

16. A.G. Kоккаlis, O.K. Panagouli, Fractl evaluation of pavement skid resistance variations. I: Surface Wetting. Chaos, Solitons and Fractals, 9, 11, p. 1875-1890, 1998.

17. R.S. McDaniel, B.J. CoReE, Identification of laboratory techniques to optimize Superpave HMA Surface Friction Characterization. Phase I. Final Report SQDH 2003-Lafayette. Indiana, 2003.

18. K. NeaYlon, The PAFV and road friction. AAPA $13^{\text {th }}$ International Flexible Pavements Conference, 11-14 October 2009, Queensland, Australia, 2009.

19. D.A. Noyce, H.U. BAhiA, J.M. Yамвo, G. KIM, Incorporating road safety into pavement management: maximizing asphalt pavement surface friction for road safety improvements. Midwest Regional University Transportation Center TOPS Laboratory, 2005.

20. J.M. Pardillo Mayora, R.J. Piña, An assessment of the skid resistance effect on traffic safety under wet-pavement conditions. Accident Analysis and Prevention, 41, 4, p. 881-886, 2009.

21. P.G. RoE, S.A. HARTSHoRne, The Polished Stone Value of aggregates and in-service skidding resistance. TRL Report 322, United Kingdom, 1998. 
22. A.B. Slimane, M. Khoudeir, J. Brochard, M.-T. Do, Characterization of road microtexture by means of image analysis. Science Direct Wear, 264, p. 464-468, 2008.

23. A.R.G. VAN DE WALL, The polishing of aggregate used in road construction. The relation between the Polished Stone Value and the petrography and mechanic properties of road aggregate, Faculty of Mining and Petroleum Engineering, Section of Engineering Geology. No. 96; T.U. Delft, 1992.

24. M. WasILEWSKA, The influence of characteristic aggregate on skid resistance pavement roads [in Polish], PhD. Bialystok Technical University. Bialystok, 2010.

25. J.C. Wambold, C.E. Antle, J.J. Henry, Z. Rado, International PIARC Experiment to Compare and Harmonize Texture and Skid Resistance Measurements. Final Report submitted to the Permanent International Association of Road Congresses (PIARC), State College, PA. 1995.

26. D.J. Wilson, R. Dunn, Polishing Aggregates to Equilibrium Skid Resistance. International Conference Surface Friction, 1-4 May 2005 Christchurch, New Zealand, 2005.

27. D.J. WILSON, P.M. BLACK, The skid resistance performance of natural New Zealand aggregates using a dynamic friction tester. Quarterly Journal of Engineering Geology and Hydrogeology, 42, 1, p. 61-72, 2009.

28. C.F.J. Wu, M.S. Hamada, Experiments: Planning, Analysis, and Optimization, $2^{\text {nd }}$ Editon, Wiley 2009.

Remarks on the paper should be sent to the Editorial Office

no later than March 30, 2013
Received September 25, 2012 revised version

December 3, 2012 